\title{
VIII
}

\section{FUNDO PATRIMONIAL E PRECARIZAÇÃO DA UNIVERSIDADE PÚBLICA: A AGENDA DO CAPITAL PARA A EDUCAÇÃO SUPERIOR BRASILEIRA*}

\author{
Janaina Duarte \\ Kátia Lima \\ Livia Prestes \\ Viviane de Queiroz
}

\section{Introdução}

O capítulo tem como objetivo apresentar um conjunto de reflexões realizadas por pesquisadoras de três universidades públicas: Universidade de Brasília, Universidade Federal Fluminense e Universidade do Estado do Rio de Janeiro. Nessas universidades, atuantes no Grupo de Estudos e Pesquisas em Educação e Serviço Social/GEPESS/UFF e no Grupo de Estudos PolíticoSociais/POLITIZA/UnB e em diálogo com as lutas realizadas pelo movimento sindical em defesa da valorização do trabalho docente e da universidade pública, estudamos um conjunto de profundas alterações na educação superior conduzidas pela agenda do capital.

Em um primeiro momento do texto, problematizamos os principais elementos estruturantes da educação superior em um país marcado por sua inserção capitalista dependente na economia mundial. Se no capitalismo a educação nasce com as funções de formar força de trabalho, difundir a concepção burguesa de mundo e configurar-se como campo de exploração lucrativa para o capital; no capitalismo dependente, tais funções assumem contornos muito específicos sob a condução de uma burguesia extremamente agressiva e conservadora, como analisava o saudoso intelectual militante Florestan Fernandes.

No item "Educação superior brasileira no contexto pós 2016: precarização da formação e das condições de trabalho nas universidades federais"

${ }^{*}$ DOI - 10.29388/978-65-86678-40-6-0-f.237-265 
apresentamos como a concepção da educação como campo lucrativo para o capital, historicamente conduzida pela burguesia brasileira, foi ampliada nas primeiras décadas do novo século. Um processo inscrito no reordenamento do padrão de acumulação e dominação do capitalismo contemporâneo nos países centrais e que atinge contornos mais agressivos nos países da periferia capitalista, pela contrarreforma do Estado brasileiro e da educação superior. O resultado deste processo está expresso na precarização da formação profissional e das condições de trabalho nas universidades públicas, particularmente, as universidades federais e, também, pelo estímulo aos fundos patrimoniais. O exame do significado político e acadêmico desses fundos é realizado no último item do texto. Apresentados pelo capital como fontes de financiamento para as políticas sociais, os fundos operam, de fato, a busca pela lucratividade realizada pelo investimento dos recursos recebidos por meio de doações no mercado financeiro, assim como, pela privatização do patrimônio das instituições públicas de ensino superior.

Os desafios que estão colocados para os que defendem a educação superior pública e gratuita na atualidade são imensos. É preciso apreender as novas estratégias de dominação burguesa e de expropriação dos direitos conquistados pelos trabalhadores, como a educação, para juntos forjarmos as lutas pela universidade pública como lócus privilegiado de produção do conhecimento crítico e criativo em consonância com as demandas históricas da classe trabalhadora.

\section{Universidade pública no capitalismo dependente}

A educação escolar na sociabilidade burguesa cumpre um papel fundamental na produção e reprodução do capital a partir da formação da força de trabalho, da difusão da concepção burguesa de mundo e como área de expansão para a lucratividade do capital. Partindo dessas considerações, buscamos analisar como tais objetivos se manifestam no capitalismo dependente e como se apresentam na conformação do padrão dependente de educação superior, como analisava Fernandes $(1981,1979)$.

O que faz do homem um ser social é a sua capacidade de realizar trabalho. Diferente dos outros animais que carregam em sua genética as informações necessárias para realizar suas funções, nós necessitamos transmitir, através de alguma forma de comunicação, os conhecimentos adquiridos e acumulados pela 
humanidade. As ações coletivas e seus resultados não são transmitidos naturalmente e a esse processo de socialização de saberes e fazer coletivo da humanidade denominamos educação. Podemos observar, com isso, que a educação tem relação direta com o que faz do homem um ser social, que é o trabalho. Bertoldo (2015) identifica a concepção de educação em dois processos: a educação em sentido restrito - inclui-se aí a educação escolar, mas não somente - e a educação em sentido lato:

A educação em sentido restrito, a exemplo da educação escolar (formal) e de outras formas de educação que se dão em espaços informais (igreja, sindicatos, etc.), é aquela criada a partir do desenvolvimento social, para responder a determinadas necessidades demandadas pelos homens, dentro de um contexto particular da história humana. A forma como esta se apresenta vai depender do momento histórico específico de produção humana. Neste sentido, a educação na Antiguidade se apresenta diferente da Idade Média, da mesma forma que se apresenta na Modernidade e assim sucessivamente. [...] Neste sentido, a educação em sentido lato, no âmbito da ontologia marxiana, somente poderá ser apreendida a partir da estrutura ontológica do trabalho. Isto porque ela tem sua origem no processo de autoconstrução humana, sendo isto que explica que enquanto existir homem haverá educação, pois esta só cessa com a extinção da humanidade. Trata-se, então, de tomar a educação na sua própria essência, para que assim possamos caracterizá-la e identificá-la a partir de sua gênese. Isto permitirá fazer a distinção, necessária, entre a educação em sentido específico e a educação em sentido lato (BERTOLDO, 2015, p. 131).

Partindo da concepção do trabalho como princípio educativo, Saviani (2003) analisa as formas de produzir e socializar conhecimentos em diferentes momentos da história humana. $\mathrm{O}$ autor ressalta que, antes da sociedade dividida em classes, não existia a separação entre trabalho e educação, uma vez que o processo educativo se dava na própria realização do trabalho. No mesmo sentido, Rodrigues (2016) identifica o surgimento da educação formal ou educação no sentido estrito associado ao cenário histórico da sociedade de classes. É a partir da apropriação privada da terra, principal meio de produção à época, que surge a divisão social do trabalho, gerando a separação entre trabalho e educação, uma vez que a classe dos proprietários passa a viver do trabalho alheio e a controlar e sistematizar, conforme sua concepção, saberes que foram construídos coletivamente nesse processo de trabalho. 
Saviani (2003) analisa que a divisão social em classes, também irá gerar uma divisão no processo educativo, criando assim uma separação entre a classe proprietária, que tinha uma educação centrada nas atividades intelectuais, filosóficas e nos exercícios físicos de caráter lúdico ou militar e a classe não proprietária, realizando seu processo educativo na própria realização do trabalho. $\mathrm{O}$ autor destaca que a origem das escolas se deu a partir da educação ofertada à classe proprietária, o que perpetrou a divisão entre trabalho e educação. É nesse contexto que surge a divisão entre os que "pensam", aqueles que se apropriam dos saberes coletivamente adquiridos e difundem seus valores como universais, e os que "executam", a maioria da população que é expropriada das riquezas coletivamente produzidas através de seu próprio trabalho.

A educação escolar surge, portanto, a partir de demandas criadas pelo próprio homem no desenrolar histórico e, em determinados períodos, apresentam diferenciadas formas, de acordo com a configuração histórica e espacial da luta de classes. Ainda que a educação escolar passe por sucessivas transformações, a depender das demandas históricas dos modos de produção e reprodução,

[...] a dualidade não é uma invenção do sistema educacional e nem mesmo do modo de produção capitalista. Como nos ensinou o mestre Mario Manacorda, a dualidade estrutural da educação atravessa os séculos, desde a constituição das sociedades divididas em classe, logo não podemos ingenuamente esperar a superação da dualidade estrutural da educação no seio de sociedades classistas. Por consequência, não é crível que decretos presidenciais eliminem as desigualdades sociais oriundas da estrutura de classes (RODRIGUES, 2005, p. 265).

Neste sentido, a educação escolar no capitalismo não é isenta de contradições e, nesse caso, especificamente, a contradição que se apresenta é fundamental para entendermos as funções econômicas, políticas, sociais e ideo-culturais da educação escolar no modo de sociabilidade do capital, uma vez que, devido à necessidade de expandir e desenvolver suas forças produtivas, as classes dominantes precisam socializar, de alguma forma, parte desses conhecimentos, no entanto, buscando sempre aprimorar formas de fragmentar e limitar cada vez mais esse processo. A educação escolar, concebida a partir dessa dualidade própria da sociedade de classes, é fundamental para a expansão do próprio capitalismo. $\mathrm{Na}$ educação básica busca socializar conhecimentos estritamente limita- 
dos e compartimentados à classe trabalhadora para a produção, e, na educação superior, produz força de trabalho mais especializada, conforme as necessidades do capital, para além da formação de quadros das classes dominantes e pesquisas que auxiliem no avanço das ciências para o desenvolvimento capitalista (PRESTES, 2018).

O papel do Estado nesse processo de condução das políticas de educação vinculadas à necessidade do capital é fundamental. Minto (2006) discute a relação entre o público e o privado numa perspectiva histórica, considerando que essas concepções devem ser analisadas a partir de cada realidade concreta. No Brasil, por exemplo, assumir como categorias analíticas a relação público/ privado, onde o público se refere ao que é diretamente estatal e o privado ao que remete aos setores das classes burguesas confunde mais do que auxilia no entendimento desta dinâmica, pois, tal procedimento não considera o papel do Estado (burguês) enquanto condutor das políticas de interesse das classes dominantes, omitindo o antagonismo entre as classes.

Por ter relação direta com a produção e reprodução da vida social, a educação escolar acompanha o desenvolvimento capitalista de uma determinada região/nação, assumindo diferentes papéis no desenrolar histórico, variando de acordo com o tempo e o espaço. É um espaço contraditório que também reproduz as tensões e os conflitos que surgem na luta de classes. É necessário, portanto, refletirmos as particularidades da educação superior em um país capitalista dependente, como o Brasil.

A dinâmica desigual e combinada do capitalismo ${ }^{1}$ abordada por Lênin (2011) e Trotsky (1977) será recuperada, em diversas obras, por Florestan Fernandes para análise do desenvolvimento do capitalismo no Brasil. Tal desenvolvimento ocorreu nos marcos da articulação do padrão compósito de dominação burguesa $^{2}$ e do padrão dual de expropriação do excedente econô-

\footnotetext{
${ }^{1}$ A teoria do desenvolvimento desigual e combinado nos permite captar a relação dialética e contraditória entre os países e/ou regiões circunscritos no desenvolvimento capitalista, de forma que, ao contrário do que prega a ideologia do desenvolvimento, os países dependentes não estão numa corrida em busca do desenvolvimento dos países centrais, e sim, cumprem esse papel de forma integrada à lógica do capital.

2 Diferente de outras burguesias que construíram suas próprias instituições e alcançaram uma hegemonia através também de alianças populares para a disputa de poder com as instituições anteriores, a burguesia local não adquiriu esses mecanismos e surgiu na realidade capitalista dependente impondo-se no plano político, através de acordos pelo alto com as elites oligárquicas, excluindo deliberadamente a maior parte "dos de baixo". Dessa forma as oligarquias não só não perderam seu poder, como foram se modernizando para adequar-se às necessidades do capital. A essa unidade entre as burguesias locais e as oligarquias, que em conjunto com as burguesias imperialistas mantém as relações de dominação no poder, Fernandes caracterizou como padrão
} 
mico $^{3}$ como elementos fundamentais para refletirmos também o papel da educação em nosso país.

[...] o Brasil não viveu, nem como colônia nem posteriormente, a experiência histórica da universidade ilustrada; e as condições da economia escravista contribuíram sensivelmente para reduzir ao mínimo as funções criativas da escola superior isolada. De outro lado, a perspectiva política da camada senhorial não estabeleceu conexões vitais entre o ensino superior, o desenvolvimento da cultura e as potencialidades de uma revolução nacional e democrática (FERNANDES, 1984, p. 32). ${ }^{4}$

\section{A educação escolar no Brasil tem uma marca muito forte da educação} oligárquica e elitista, eixo que também caracteriza o processo que Fernandes (1981) denominou como traço colonial permanente. ${ }^{5}$ Ainda que no decorrer do processo histórico tenham ocorrido mudanças na organização da educação escolar, especialmente na educação superior, esse caráter estruturante de exclusão dos trabalhadores do acesso à educação se mantém, principalmente pela concepção da educação como privilégio e do privatismo exaltado, como identificava Fernandes (1979).

O padrão brasileiro de escola superior nunca deitou raízes em concepções, processos ou valores educacionais que foram vitais para a revolu-

compósito de dominação burguesa.

${ }^{3} \mathrm{O}$ padrão compósito de dominação burguesa e o padrão dual do excedente econômico são as duas principais categorias que nos ajudam a entender o que Fernandes (1981) denomina de capitalismo dependente. Para o autor, o padrão de dominação externa imperialista repercutiu principalmente na manutenção da produção de matérias primas de bens primários dentro da lógica já posta de exportação-importação condicionando e agravando as estruturas econômicas arcaicas. Esse elemento contribuiu para a não integração nacional dos países dependentes (em todas as dimensões), tendo a transferência do excedente econômico um papel determinante para a intensificação desse padrão e reforçando a associação entre as nações imperialistas e as elites locais que, conforme nos mostra, formou-se a partir de interesses particularistas e viram na associação subordinada e dependente um meio menos "arriscado" de lucrar.

${ }^{4} \mathrm{~A}$ educação escolar no Brasil tem uma marca muito forte da educação oligárquica e elitista, eixo que também caracteriza o processo que Fernandes (1981) denominou como traço colonial permanente

5"Florestan Fernandes analisa a acumulação capitalista em países capitalistas dependentes considerando que a ausência de uma acumulação originária suficientemente forte para sustentar um desenvolvimento autônomo gerou a transição das economias coloniais para o capitalismo pela inclusão subalternizada na economia mundial e pela manutenção das bases políticas e socioculturais do sistema colonial associado ao impulso da industrialização e urbanização, caracterizando, assim, o traço ou condição colonial permanente em constante processo de revitalização" (LIMA, 2017, p. 354). 
ção do mundo moderno, na Europa e nos Estados Unidos. Ao contrário, ele se prendia a uma composição de resíduos educacionais ou institucionais arcaicos com interesses estamentais ou de classes, que só poderia ter algum sentido dinâmico no contexto histórico da formação do capitalismo dependente no Brasil. Não só estava montado para servir às relações de dependência; dava suporte a uma orientação tipicamente conservadora, que esvaziava a contribuição das escolas superiores para a transplantação cultural de significado histórico mais ou menos perturbador (FERNANDES, 1979, p. 113).

Ao longo de suas obras, Fernandes aprimorou a categoria de heteronomia cultural, organicamente vinculada ao conceito de capitalismo dependente. Limoeiro-Cardoso (1996) ressalta que, desde seus primeiros escritos, o autor dá uma centralidade para a dimensão cultural na interpretação da formação econômica social-brasileira e seus limites enquanto "nação".

A partir do seu aprofundamento teórico no materialismo histórico e dialético e do acirramento da luta de classes no país, Fernandes identifica nas suas pesquisas que em diferentes países que tinham uma maior "autonomia nacional", no sentido de desenvolver-se culturalmente, ainda assim mantinham seu caráter dependente, o que o levou a concluir que a heteronomia cultural não era o principal entrave da ruptura com a dependência, sendo ela também uma consequência dessa. Se povos com cultura própria, rica e complexa também se encontram em condição heteronômica, a dependência cultural não pode ser tão central à condição dependente, menos ainda responsável por ela, ainda que possa ser muito importante (negativamente) na luta contra ela. Com isso, a cultura não se ausenta das preocupações de Florestan. Mas aparece cada vez mais tematizada enquanto ideologia e cede espaço a reflexões mais propriamente econômicas e políticas. Condizente com essa nova perspectiva, as classes sociais e suas relações passam a ganhar destaque e centralidade nas suas análises (LIMOEIRO-CARDOSO, 1996, p. 108).

A problemática da heteronomia cultural é uma questão importante para entendermos os desafios educacionais no Brasil. Fernandes (1974) reforça que a heteronomia não é apenas a absorção de ideias e valores externos, mas sim a internalização e esquematização desses valores para a realidade nacional, constituindo uma das faces do projeto burguês de sociabilidade no capitalismo dependente. A própria dificuldade de realização de pesquisas que pensem a realidade 
brasileira na sua particularidade, mas relacionada com o modo de sociabilidade do capital, evidencia esse traço heteronômico.

A tendência a procurar na Europa ou nos EUA a satisfação de conjunto de centros de interesses e de valores alimenta um processo de alienação intelectual e moral de imensas proporções. Ao contrário do que se supõe comumente, o fato crucial não está, aqui, na procedência externa de categorias de pensamento e dos modos de agir, mas na maneira de interligálos, que toma como ponto de referência permanente os núcleos civilizatórios estrangeiros, em que foram produzidos. Daí resulta um estado de dependência fundamental. Com isso, o processo de desenvolvimento interno se entrosa com valorizações e disposições subjetivas que concorrem, diretamente, para perpetuar e fortalecer a condição heteronômica da sociedade brasileira (FERNANDES, 1974, p. 172).

No Brasil, portanto, as universidades derivaram do padrão brasileiro de escola superior associado à heteronomia cultural, como analisava Fernandes (1979):

Existe, naturalmente, uma limitação estrutural, ou seja, uma limitação que é padronizada e geral, que aparece em todas as escolas superiores brasileiras. Isso nos obriga a falar de algo muito complexo para esta discussão: trata-se do padrão brasileiro de escola superior. [...] A escola superior brasileira constituiu-se como uma escola de elites culturais ralas e que apenas podiam (ou sentiam a necessidade de) explorar o ensino superior em direções muito limitadas. Como a massa de conhecimentos procedia do exterior e a sociedade só valorizava a formação de profissionais liberais, a escola superior tornou-se uma escola de elites, de ensino magistral e unifuncional: cabia-lhe ser uma escola de transmissão dogmática de conhecimentos nas áreas do saber técnico-profissional, valorizadas econômica, social e culturalmente pelos extratos dominantes de uma sociedade de castas e estamental (FERNANDES, 1979, p. 56).

Entender como o padrão dependente de educação superior e a heteronomia cultural inerente ao capitalismo dependente se manifestam na atualidade são tarefas urgentes e necessárias. A partir da compreensão de que o privatismo exaltado e a concepção da educação como privilégio são elementos estruturantes da educação superior no capitalismo dependente, buscaremos identificar, a seguir, suas manifestações atuais, no Brasil. 


\section{Educação superior brasileira no contexto pós-2016: pre- carização da formação e das condições de trabalho nas universidades federais}

O reordenamento do padrão de acumulação e dominação do capitalismo contemporâneo nos países centrais atinge contornos mais agressivos nos países da periferia capitalista, principalmente a partir dos anos 2000, por meio das suas repercussões no Estado, nas condições e relações de trabalho, na cultura, na estrutura do poder político e econômico fundado na sociabilidade burguesa. Em um país marcado pela inserção capitalista dependente na economia mundial, a pauta ultraconservadora do capital instaurada no novo século ganha contornos bastante definidos.

$\mathrm{Na}$ conjuntura brasileira, as contrarreformas neoliberais ${ }^{6}$ do Estado iniciadas na década de 1990 têm avançado, respondendo às insaciáveis requisições e demandas do capital, a partir dos eixos flexibilização, desregulamentação e privatização. Tal cenário tem exposto a Política de Educação Superior brasileira a um conjunto de contrarreformas neoliberais, pautadas pela concepção de educação como serviço não exclusivo do Estado, em detrimento da garantia do direito à educação, com ênfase na produtividade, no empresariamento da educação e na certificação em larga escala (LIMA, 2007), alterando a lógica da formação e as condições de trabalho nas universidades públicas.

Diante das contrarreformas situadas no âmbito da política de educação superior, alguns traços são essenciais e precisam ser resgatados: a) a expansão da privatização, iniciada com a ditadura, ${ }^{7}$ transformando o ensino superior em área de investimento (e lucratividade) amplificado do capital, incluindo a pósgraduação; b) o comprometimento do tripé ensino, pesquisa e extensão, dificultando sua realização com o crescimento do ensino à distância, os cortes de recursos públicos nas universidades públicas, bem como fragmentando a lógica desta tríade, o que vem alterando o significado da universidade e suprimindo seu caráter universalista; c) a subordinação da formação e da produção do co-

${ }^{6}$ Conforme Lima (2007), o termo contrarreforma da educação superior expressa as profundas alterações neoliberais que estão em curso na política educacional brasileira, ao contrário de reformas que alteram substantivamente as condições de vida dos(as) trabalhadores(as) (ainda que nos limites do capitalismo), destroem direitos e submetem a educação ao patamar de serviço comercializável (e lucrativo), como nicho de exploração do capital.

7 A Reforma Universitária de 1968 ampliou o ensino superior e as funções da universidade, a partir de um processo determinado pela naturalização da privatização e pela repressão (DUARTE, 2017). 
nhecimento ao mercado, pois a vida universitária passa a ser organizada em função do capital, por meio do mercado, a fim de atender seus estritos interesses e demandas; e d) a redução da autonomia universitária, o que confere a essa um sentido bastante específico, ${ }^{8}$ introduzindo termos como qualidade universitária, avaliação universitária e flexibilização da universidade, bem como, incorporando a lógica da organização social, em detrimento da concepção de instituição universitária; ${ }^{9}$ e) a precarização e intensificação do trabalho docente, com a flexibilização da carreira, a sobrecarga de trabalho pautada pela lógica empresarial das atividades acadêmicas e da produção do conhecimento, acarretando desdobramentos para saúde deste/a trabalhador/a.

Este processo vai transformando a universidade pública de produtora de conhecimento em universidade operacional (CHAUÍ, 1999), perdendo seu caráter universal e sendo estruturada por normas e padrões inteiramente alheios ao conhecimento e à formação intelectual, manifestando, assim, a atualidade do padrão dependente de educação superior inerente ao capitalismo dependente, conforme analisado anteriormente. Seu pressuposto é a competitividade e as estratégias particulares, reforçando o individualismo e o mérito individual, o que contribui para a diluição da fronteira público e privado, que será ampliada a partir da ação dos fundos patrimoniais, como analisaremos mais adiante.

Nos primeiros anos do novo século, é importante registrar que a política de educação superior direcionou-se para: 1) as parcerias público-privadas, tanto no financiamento de pesquisas e atividades de interesse mercantil, como na interferência no cotidiano do funcionamento da vida acadêmica e na produção do conhecimento nas universidades; $;^{10}$ 2) a abertura do setor educacional

\footnotetext{
${ }^{8}$ Autonomia aqui vem significando o gerenciamento empresarial da instituição e prevê que, para cumprir as metas e alcançar os indicadores impostos pelo contrato de gestão, a universidade tem "autonomia" para "captar recursos" de outras fontes, fazendo parcerias com as empresas privadas (CHAUÍ, 1999).

9 A instituição tem a sociedade como seu princípio e sua referência normativa e valorativa; enquanto a organização tem apenas a si mesma como referência, num processo de competição com outras, cujos objetivos particulares são pautados pelas ideias de eficácia, gestão, planejamento, controle (CHAUÍ, 1999).

${ }^{10}$ Como suporte jurídico têm-se a Lei da Inovação Tecnológica $(10.973 / 2004)$, que flexibiliza as fronteiras entre o público e privado por meio de convênios entre universidades, centros de pesquisa e empresas, inclusive com a "[...] utilização, pelo setor privado, de infraestrutura, equipamentos e recursos humanos das IES públicas" (LIMA, 2007, p. 174); e o Decreto $\mathbf{n}^{\mathbf{o}}$ 7.423/2010 que formaliza as Fundações de Apoio Privadas e sua relação com as instituições federais, para a captação de recursos privados voltados para os interesses das
} 
superior para empresas e grupos estrangeiros, principalmente com o estímulo ao EaD e com estratégias como o Programa Universidade para Todos (ProUni) e o Fundo de Financiamento ao Estudante do Ensino Superior (Fies); em detrimento do 3) desmonte do setor público da educação superior, com redução contundente de investimentos públicos, intensificação do trabalho docente, precarização da estrutura física, especialmente pelo Programa de Reestruturação e Expansão das Universidades Federais (REUNI), ${ }^{11}$ promovendo "[...] um sucateamento planejado e sistemático das universidades públicas, enraizando ainda mais o vasto sistema privado de educação na sociedade brasileira" (LEHER, 2010, p. 371).

A partir de 2016, o Governo Temer, ${ }^{12}$ de forma mais agressiva, aprova a Emenda Constitucional 95/2016 que congela os investimentos públicos por 20 anos em políticas púbicas. ${ }^{13}$ Disso resulta que os investimentos públicos em saúde e educação terão, em termos reais, os mesmos valores de 2017, desconsiderando o crescimento da população brasileira e as demandas sociais pela ampliação do acesso à saúde e à educação públicas. Além do congelamento na alocação das verbas públicas para as políticas públicas, a EC 95/2016 congela os reajustes salariais de funcionários públicos e a realização de concursos públicos. Apesar das lutas da classe trabalhadora contra a sua aprovação, a PEC foi promulgada, como EC 95, em 15/12/2016.

A lógica privatizante que caracteriza o padrão dependente de educação superior no Brasil será aprofundada e ampliada no governo Michel Temer (2016/2018). O tripé ajuste fiscal para o pagamento dos juros e amortizações da dívida pública; diminuição da alocação da verba pública para o financiamento das políticas públicas, entre estas, a educação superior, e fortalecimento do setor privado, via fundo público, constituiu o eixo condutor da contrarreforma

administrações das universidades ou grupos de professores, ou ainda para a contratação de pessoal sem concurso, e a cobrança de cursos e projetos coordenados por docentes.

11 O REUNI, regulamentado pelo Decreto Presidencial 6.096/07, abriu vagas em universidades públicas, mas desconsiderando a situação de sucateamento das federais e o déficit de professores, sendo explícita a sobrecarga da estrutura já insuficiente, com bases precárias, e a intensificação do trabalho, comprometendo a qualidade do ensino e o acompanhamento dos alunos, com desrespeito às requisições voltadas para o tripé ensino, pesquisa e extensão.

12 Várias são as análises para o golpe de 2016, no entanto, considera-se que a principal foi a rearticulação das frações da burguesia local, de cunho mais conservador, na direção do aprofundamento mais agressivo do projeto da classe dominante, culminando com a perda do $2^{\circ}$ mandato de Dilma e a formalização do governo de Michel Temer, sem eleição direta, caracterizando de fato um golpe em termos políticos.

13 Além da aprovação de reformas regressivas, tais como a Lei de Terceirização (Lei 13.429/2017) e a Reforma Trabalhista (Lei 13.467/2017). 
do Estado e da educação superior no referido período. Em 2017, 39,70\% do Orçamento Geral da União (OGU) foi alocado para o pagamento dos juros e amortizações da dívida pública, equivalendo a $\mathrm{R} \$ 986.110 .833 .381,14$, ou seja, quase 1 trilhão de reais, enquanto 4,10\% foi direcionado para a educação (AUDITORIA CIDADÃ DA DÍVIDA, 2018).

O tempo atual revela ainda mais agressividade na agenda do capital, particularmente para os países capitalistas dependentes, como o Brasil. Segundo Leher (2019), o governo Bolsonaro se caracteriza a partir da negação de tudo o que já está consolidado no campo científico, ainda somado à violência e ao controle ideológico. Portanto, o governo atual tende a ser contra a ciência, a arte e a cultura em geral (LEHER, 2019), a todas as formas de expressão que estimulem o pensamento crítico.

O ataque do capital à educação ganha expressão no Plano de Governo Bolsonaro (2018/em curso). O exame do "Plano de Governo Bolsonaro - O Caminho da Prosperidade" revela as linhas centrais condutoras da Política de Educação Superior para o período 2019-2022: “Conteúdo e método de ensino precisam ser mudados. Mais matemática, ciências e português, SEM DOUTRINAÇÃO E SEXUALIZAÇÃO PRECOCE. Além disso, a prioridade inicial precisa ser a educação básica e o ensino médio/técnico" (PARTIDO SOCIAL LIBERAL, 2018, p. 41, grifos do autor). Para tal, defende mudar a gestão escolar; modernizar o conteúdo das disciplinas e "expurgar a ideologia de Paulo Freire" (PARTIDO SOCIAL LIBERAL, 2018, p. 46) das escolas e universidades. O Plano de Governo também indica os seguintes eixos condutores das ações do governo Bolsonaro para a educação superior:

As universidades precisam gerar avanços técnicos para o Brasil, buscando formas de elevar a produtividade, a riqueza e o bem-estar da população. Devem desenvolver novos produtos, através de parcerias e pesquisas com a iniciativa privada. Fomentar o empreendedorismo para que o jovem saia da faculdade pensando em abrir uma empresa [...] Educação à distância: deveria ser vista como um importante instrumento e não vetada de forma dogmática (Idem, p. 46).

É neste contexto de ofensiva ultraconservadora que o Governo Federal apresenta o "Programa Institutos e Universidades Empreendedoras e Inovadoras. Future-se" indicando às Instituições Federais a captação de recursos junto ao setor privado por meio dos fundos de investimento, das parcerias públicoprivadas e da privatização do patrimônio imobiliário das universidades federais, 
cuja gestão passará a ser feita, segundo o programa, por Organizações Sociais (OS’s), de caráter privado (UFLA, 2019). O programa foi dividido em três eixos: Gestão, Governança e Empreendedorismo; Pesquisa e inovação; e Internacionalização, propondo a assinatura de contrato de gestão entre a União e cada Instituição Federal de Ensino Superior (IFES), celebrado com Organizações Sociais (OS’s) já qualificadas pelo Ministério da Educação ou por outros Ministérios, sem a necessidade de chamamento público. O referido contrato de gestão estabelecerá, pelo prazo de quatro anos, metas de desempenho e indicadores de produtividade para as Instituições Federais de Ensino. Às OS’s caberá realizar o processo de gestão dos recursos relativos a investimentos em empreendedorismo, pesquisa, desenvolvimento e inovação e atuar na gestão patrimonial dos imóveis das IFES participantes. À União e/ou às IFES caberá repasse de recursos orçamentários e permissão de uso de bens públicos pelas OS’s, assim, os bens imobiliários das IFES constituir-se-ão em fontes de recursos para o programa.

Em relação ao MEC, poderá participar como cotista de fundos de investimento, (fundos de natureza privada), cujos níveis de rentabilidade estarão definidos nos estatutos de cada fundo e, também, poderá doar bens imobiliários para as OS's participantes do contrato de gestão. As atividades acadêmicas das IFES, em consonância com as OS's, têm como principais objetivos a inovação, incluídos parques e polos tecnológicos; o aprimoramento de modelos de negócios e a comercialização de marcas e produtos, fomentando a arrecadação de receitas próprias e a empregabilidade para os alunos das instituições, gerando, nos termos do documento apresentado pelo MEC, uma efetiva aproximação entre as instituições de ensino e o setor privado.

Será permitida também a criação de Sociedade de Propósito Específico (SPE), no formato de microempresas, por departamento ou pelas IFES para venda do que o Governo Federal considera como serviços educacionais, especialmente de pesquisa e inovação, bem como, nomear uma parte de um bem, móvel ou imóvel, de um local ou evento, em troca de compensação financeira.

O programa defende, portanto, o autofinanciamento ou a autonomia financeira das IFES (ferindo o artigo 207 da Constituição Federal de 1988 que trata da autonomia de gestão financeira), conforme está explícito no artigo 23, por meio das seguintes ações: (i) venda de estudos, pesquisas, consultorias e projetos; (ii) a comercialização de bens e produtos com a marca das instituições de ensino; (iii) alienação de bens imobiliários das instituições pela venda, alugueis e concessões; (iv) aplicações financeiras que cada instituição realizar na di- 
nâmica da bolsa de valores; (v) exploração de direitos de propriedade intelectual das pesquisas realizadas por docentes e estudantes; (vi) cobrança de matrículas e mensalidades de pós-graduação lato sensu nas universidades federais; (vii) ganhos de capital e os rendimentos oriundos dos investimentos realizados com seus ativos; (viii) recebimento de quantias em decorrência das leis de incentivo fiscal e (ix) recebimento de rendas provenientes de outras fontes de captação.

O Future-se só pode ser analisado articulado à EC 95/2016, pois, em um contexto de ausência de financiamento público para a educação superior pública, objetiva o aprofundamento de um modelo de financiamento (privado) e de gestão (empresarial), ressignificando as funções político-pedagógicas da educação pública, esvaziando o sentido de produção e socialização do conhecimento crítico e criativo e a busca de soluções para os problemas sociais urgentes de um país capitalista dependente, substituídos pela venda de serviços educacionais e de bens imobiliários das instituições públicas, e pelo investimento no lucrativo mercado financeiro (LIMA, 2019).

Diante deste contexto, podemos afirmar que diversos e abrangentes são os desafios (im)postos para a formação e o trabalho nas universidades públicas, especialmente as federais, no período pós-2016:

\section{- Precarização da Formação:}

a) aligeiramento da formação profissional com o $\mathrm{EaD}$, especialmente pelo crescimento dos cursos privados, dificultando o acesso dos estudantes a uma educação que contenha pesquisa e extensão, com incentivo à capacidade investigativa e propositiva que fuja das respostas imediatas indicadas pelo mercado;

b) incidência determinante do mercado no ensino, na pesquisa e na produção do conhecimento, além de comprometer a formulação de questões (e a busca por respostas) que atinjam a coletividade e que afligem de fato a classe trabalhadora;

c) tendência de descaso com o rigor teórico metodológico/científico diante do estímulo à imediaticidade posta como realidade, desqualificando a distinção fundamental entre aparência e essência;

d) formação voltada para o fornecimento imediato de mão de obra necessária à reprodução do capital, em detrimento da educação como possibilidade também de desenvolvimento de capacidades humanas e que pense a sociedade e seus problemas de forma crítica; 
e) estímulo a um perfil profissional que não preze pelo conhecimento crítico que garanta o entendimento da complexidade da realidade social e das profissões nela inserida.

- Dinâmica combinada de precarização e intensificação das condições de trabalho na universidade:

a) desprestígio ao/à servidor/a público/a, inclusive com ações de alteração das carreiras e redução de concursos públicos;

b) sobrecarga e intensificação do trabalho, em quantidade e qualidade de atividades;

c) exacerbação do individualismo e da competitividade no cotidiano de trabalho acadêmico, afetando docentes, técnicos administrativos e discentes;

d) adoecimento do coletivo do "mundo acadêmico" e a dificuldade no cumprimento de prazos de conclusão dos trabalhos acadêmicos (monografias, dissertações de mestrado e teses de doutorado);

e) produção do conhecimento mais voltada para a quantificação, em detrimento da qualificação, ou seja, estímulo ao produtivismo acadêmico, especialmente pelos órgãos de fomento à pesquisa; e

f) precariedade das condições objetivas de trabalho (infraestrutura geral e salários baixos), tanto de técnicos administrativos como de docentes, conduzindo ao descaso com os investimentos no tripé ensino/pesquisa/ extensão.

Fica evidente que o capital avança em seu ataque à educação pública, pela materialização do privatismo exaltado inerente ao padrão dependente de educação superior constitutivo do capitalismo dependente, como analisava Florestan Fernandes. Tal ataque ganha, com os fundos patrimoniais, um novo patamar. Examinar o significado político e acadêmico desses fundos é a tarefa que realizaremos a seguir.

\section{Fundo patrimonial nas universidades federais: a pauta do capital para a educação superior}

Privatismo exaltado e concepção da educação como um privilégio de classe tem se constituído em dois eixos estruturantes do padrão dependente de educação superior no capitalismo dependente. Além da ampliação da ação do setor privado pelo aumento do número de instituições privadas, da privatização interna das instituições públicas e do uso intensivo da verba pública para finan- 
ciamento direto e indireto do setor privado de educação superior, ${ }^{14}$ na atualidade, a agenda do capital tem buscado novas estratégias de lucratividade que resultam em profunda destruição das instituições públicas de ensino e pesquisa. Entre estas estratégias, destacamos os fundos patrimoniais.

Os fundos patrimoniais constituem-se em conjuntos de ativos de natureza privada conhecidos também como endowmentfund ${ }^{15}$ ou fundos filantrópicos - estruturas financeiras criadas por instituições de diversas naturezas. São formados por uma soma de recursos provenientes de doações e heranças, onde o valor principal é aplicado no mercado financeiro (fundos de investimento) gerando rendimentos que são direcionados para diversas iniciativas em longo prazo. Os objetivos e estratégias para a criação desses fundos se dão de formas diferentes, de acordo com a tipificação das instituições, que podem ser: a) Fundações Familiares; b) Fundos Independentes ou Organizações da Sociedade Civil (OSC); c) Fundações Empresariais. Segundo Fontes (2020, p. 20), esses aparelhos privados de hegemonia (APHs) empresariais

[...] acedem mais facilmente a posições no Estado, inclusive modificando dispositivos legislativos, e dão caráter "estatal-legal" a certas elaborações que, voltadas para áreas particulares, corporativas (no sentido de responderem a alguns setores específicos), tornam-se imposições da generalização de tais interesses, como se fossem interesses de todos.

A autora destaca que a sociedade civil empresarial busca bloquear, dentro e fora do Estado, a participação dos movimentos sociais combativos e classistas, sendo necessário pensar esse ativismo de setores dominantes - indústria, finanças, serviços, agronegócio - na política educacional ${ }^{16}$ associado aos fundos patrimoniais. No mesmo sentido, Neves (2005) analisa como a nova pedagogia de hegemonia aponta as novidades e continuidades das estratégias do capital para (des)educar os/as trabalhadores/as, tendo como ponto em comum a teoria do capital humano nas ações educativas de fortalecimento do projeto de sociabilidade burguesa.

\footnotetext{
14 Cf. Lima (2007), Rodrigues (2007), Sguissardi (2008), Minto (2011), Leher (2018).

15 Segundo Fabiani (2012), endowment é o termo original em inglês no que se convencionou a definir, no Brasil, como fundo patrimonial.

${ }^{16}$ Leher (2018) apresenta a atuação das grandes empresas que estão entre os duzentos maiores grupos econômicos atuantes no Brasil e intervêm diretamente na educação básica, profissional e superior - programam suas ações por meio de suas entidades empresariais, os aparelhos privados de hegemonia (APHs).
} 
Estas novidades e continuidades dos dilemas da educação superior na atualidade são constitutivas das ações ofensivas do capital por meio das orientações políticas do Estado - conduzidas pela ofensiva reacionária da burguesia brasileira, em uma nova fase da histórica dualidade educacional e do privatismo da educação superior constitutivas do padrão dependente de educação superior inerente ao capitalismo dependente, conforme analisado.

Há tempos as IFES se deparam com grandes bloqueios e cortes orçamentários que atingem diretamente as condições de formação e de trabalho nestas instituições. Esse quadro de redução de recursos públicos se intensifica com o congelamento dos gastos sociais e o governo Bolsonaro, na atualidade, apresenta como alternativa de financiamento uma política que altera os eixos históricos que sustentam o caráter público das IFES e a função social da universidade pública no Brasil.

A elaboração do Programa Future-se, analisado anteriormente, se deu a partir do diálogo exclusivo com o mercado - a grande burguesia por meio dos APHs - para submeter a produção de conhecimento aos interesses do capital e não às necessidades dos trabalhadores. Essa proposta segue a orientação dos organismos internacionais do capital, especialmente, o Banco Mundial/BM, baseados no modelo de sistema educacional dos EUA, como a Universidade de Harvard, que contam com fundos patrimoniais (endowments), ${ }^{17} \mathrm{sem}$ considerar as particularidades da educação superior no Brasil.

Trata-se de mais uma forma de transplantação do modelo estaduniden$\mathrm{se}^{18}$ para as universidades brasileiras - nos marcos da heteronomia cultural e

17 No exterior os endowments foram os pioneiros nos investimentos de impacto e pelo retorno financeiro ao próprio investimento. O retorno do investimento se dá por meio de capital de longo prazo no mercado financeiro, com potencialidade de investimento superior aos fundos de pensão, “[...] que possuem um passivo implícito desde sua concepção. No exterior, os endowments são responsáveis por investimentos em infraestrutura, florestas, investimentos alternativos, investimentos em privateequity" (PASQUALIN, 2019, p. 49).

18 A transplantação do modelo dos Estados Unidos de educação superior prevaleceu a partir da reforma universitária consentida da ditadura empresarial-militar (FERNANDES, 1979). O sistema de educação superior norte-americano é apontado com muita frequência como um modelo a ser seguido, especialmente nos documentos dos aparelhos privados de hegemonia e destacado por diversos intelectuais orgânicos do capital - as mentes colonizadas - como algo a ser copiado no Brasil. Segundo Moraes (2015, 2017), há vários sistemas de educação superior nos Estados Unidos, não existe um sistema de ensino superior nacional, não há universidade federal nesse país, como no Brasil. Sendo um sistema descentralizado, profundamente estadualizado um modelo piramidal, diversificado e hierarquizado. O financiamento é um dos elementos importantes para demonstrar as diferenças e semelhanças entre as instituições. Todo o ensino superior nos EUA é pago pelo estudante, assim como, os cursos das instituições públicas, e o endividamento é altíssimo. Não há um sistema público e gratuito, como no Brasil. As escolas privadas, como as renomadas Harvard University e Massacbusetts Instituteof Technology (MIT), 
inerente ao padrão brasileiro de educação superior no capitalismo dependente, conforme abordado anteriormente. Os intelectuais orgânicos do capital, especialmente o BM, buscam justificar a criação de fundos patrimoniais para as universidades brasileiras, alegando que a experiência internacional comprova que os endowments representam fonte importante de receita para instituições públicas, destacando, como referência, a Universidade de Harvard. No entanto, além de ser uma instituição privada, os recursos públicos (diretos e indiretos) representam a maior parte do seu orçamento ${ }^{19}$ - o Estado financia, mas quem executa $\mathrm{e}$ gerencia os recursos públicos é a iniciativa privada. ${ }^{20}$

O debate sobre os fundos patrimoniais apresenta-se como uma novidade no Brasil, mas o caminho já estava pavimentado para a implementação e fortalecimento desse tipo de fundo pelo governo de Dilma Rousseff, com a promulgação da Lei no 13.019/2014, conhecida como o novo Marco Regulatório das Organizações da Sociedade Civil (MROSC) - o fundo patrimonial aparece pela primeira vez na legislação brasileira no art. $2^{\circ}$, I, "a" da referida lei. Em 2010, é divulgada a plataforma dos APHs por um novo MROSC e a Secretaria de Governo da Presidência da República, a partir da criação do Grupo de Trabalho Interministerial (GTI), conduziu, por meio da articulação política com as entidades mercantil-filantrópicas, ${ }^{21}$ a formulação de políticas e de uma legislação própria mais favorável à existência das entidades sem fins lucrativos.

recebem grande quantidade de verba pública. A receita derivada das aplicações dos patrimônios privados das universidades e as doações feitas por grandes milionários (ex-alunos) cobrem uma pequena parte dos orçamentos.

${ }^{19}$ De acordo com Relatório Financeiro da Universidade de Harvard (2019), as fontes de receitas da universidade contam com recursos públicos de forma direta (financiamento federal), e indireta (por meio das isenções fiscais dos "doadores"/acionistas). Disponível em: $<$ https://finance.harvard.edu/files/fad/files/fy19_harvard_financial_report.pdf>. Acesso em: 01 abr. 2020.

20 Segundo Moraes $(2015,2017)$, desde a Colônia isso ocorre no sistema de educação superior norte-americano - a doação de terras públicas e a isenção de taxas que construíram os patrimônios e estruturas das universidades dos EUA. O autor destaca o que cada setor financia e o que cada um deles executa em termos de pesquisa nos EUA - recurso federal financia grande parte da pesquisa. O governo federal financia pesquisa na indústria, nas universidades (públicas e privadas), em centros e institutos vinculados as universidades. Enquanto todas as instituições executam mais do que financiam, o governo federal financia mais do que executa.

21 Para Fontes (2010), a grande burguesia está diretamente ligada às entidades mercantilfilantrópicas no Brasil - entidades sem fins lucrativos, mas com fins engordativos - por receberem isenções e imunidades fiscais (recursos públicos para essas entidades empresariais). Além disso, esses APHs elaboram o projeto de poder para a expansão do capitalismo, buscando desqualificar qualquer forma de contestação e fortalecendo a formação de consensos. 
O I Seminário Internacional do Marco Regulatório das Organizações da Sociedade Civil (MROSC) ocorreu em novembro de 2011, definindo a atuação do GTI e a discussão de vários temas da agenda do capital, ente os quais, os Fundos Patrimoniais (endowments). Segundo Lopes (2019), assessora especial de Gilberto Carvalho (Ministro da Secretaria-Geral da Presidência da República do governo Dilma Rousseff), nesse período havia muita abertura para escuta e estímulo do governo para que as entidades sem fins lucrativos apresentassem suas propostas ao marco regulatório. Com essa articulação oficial [...] a Secretaria-Geral passou a construir pontes com o Poder Legislativo em relação ao tema. Já existia um projeto de lei no Congresso Nacional (PL 4643/2012) para criação de Fundos Patrimoniais para universidades públicas e o IDIS estava elaborando propostas dentro de um grupo de trabalho. A apresentação de proposta de projeto de lei, elaborada pelo grupo, certamente foi um aspecto que permitiu o avanço das articulações com a Secretaria-Geral da Presidência (LOPES, 2019, p. 197).

Segundo a "Proposta de Projeto de Lei - Fundos Patrimoniais Vinculados" -, ${ }^{22}$ o grupo de estudos foi constituído com a participação de representantes de 33 organizações da sociedade civil, Ministério Público, universidades e advogados, além de 57 pessoas e instituições interessadas em informações do andamento dos estudos. O grupo de estudos apresentou propostas de ampliação da criação dos endowments ao PL n ${ }^{\circ}$ 4.643/2012 e propostas da mesma natureza ao projeto de lei PLS16/2015, que tramita no Senado, além de apresentar subsídios técnicos e propostas de redação para o PL 6775/2016.

O relator da Comissão de Constituição e Justiça e de Cidadania (CCJ) da Câmara dos Deputados, deputado federal Paulo Teixeira (PT-SP), apresentou a PL 4643/2012 e, articulado com a Secretaria-Geral, seguiu a demanda do grupo de estudo coordenado pelo Instituto para o Desenvolvimento de Investimento Social (IDIS), ${ }^{23}$ pois “[...] incorporou em seu relatório a ideia da ampliação dos endowments para além das universidades públicas. Era a primeira vez que o tema aparecia no Congresso de forma a contemplar também as entidades privadas sem fins lucrativos" (LOPES, 2019, p. 197, grifos nossos). Segundo a au-

22 Fundo Patrimonial Vinculado foi o nome criado pelo Grupo de Estudos de Fundos Patrimoniais instituído pelo IDIS e Vérios que elaborou uma proposta de Projeto de Lei "Fundos Patrimoniais Vinculados". Disponível em:

$<$ http://www.secretariadegoverno.gov.br/.arquivos/fundos-patronais $>$. Acesso em: 19 nov. 2018.

${ }^{23}$ O principal APH dos Fundos Patrimoniais no Brasil. 
tora, além do IDIS, outras instituições também passaram a se dedicar ao estudo sobre o tema, como o Grupo de Institutos, Fundações e Empresas (GIFE). ${ }^{24}$

Após o incêndio que destruiu grande parte do acervo do Museu Nacional no Rio de Janeiro, em 2018, essas organizações conseguiram emplacar as suas propostas de regulamentação para as instituições com fundo patrimonial como política de governo, a partir da aprovação da Medida Provisória (MP) $n^{\circ}$ 851/2018, que visa regulamentar os Fundos Patrimoniais Filantrópicos no Brasil, assinada pelo então presidente Michel Temer, no dia 10 de setembro de 2018. Em seguida, a Lei nº 13.800/2019 que regulamenta a constituição de fundos patrimoniais foi promulgada no dia 04 de janeiro de 2019, pelo presidente Jair Bolsonaro. Esse marco legal atende à demanda do empresariado organizado que vem reivindicando essa pauta, fortalecendo as parcerias público-privadas e a nova modalidade de exploração lucrativa da educação superior. A Lei dos Fundos Patrimoniais é facultativa 25 - às entidades sem fins lucrativos que já possuem fundo patrimonial a lei não é de aplicação obrigatória -, pois é imprescindível que a instituição pública demande um Fundo Patrimonial exclusivo.

Os Fundos Patrimoniais de instituições privadas sem fins lucrativos já eram uma prática no Brasil, ${ }^{26}$ ou seja, os fundos desse tipo não surgem com a lei dos Fundos Patrimoniais e não impõem limitações aos fundos de instituições privadas já existentes. A lei cria, entretanto, novas regras, especialmente para os fundos destinados a instituições públicas. Na Câmara e no Senado Federal foram elaborados e encontravam-se em tramitação - antes da promulgação da referida lei - vários projetos de lei ${ }^{27}$ voltados para a criação de fundos patrimoniais nas universidades, instituições culturais e unidades de conservação.

No dia 09 de setembro de 2019, a matéria do jornal Valor Econômi$\mathrm{co}^{28}$ destaca que o MEC, para captar financiamento privado para pesquisa, de-

\footnotetext{
${ }^{24}$ GIFE é uma organização que se define como sem fins lucrativos que reúne o setor empresarial no Brasil - se constitui como um APH que atua como intelectual coletivo da burguesia.

${ }^{25}$ Eduardo Pannunzio (2019) afirma que o modelo de fundos patrimoniais da Lei 13.800/19 é facultativo, considerando a CF de 1988 que dedica ampla liberdade às associações. Portanto, não considera ilegal os Fundos já existentes fundados de diversas naturezas.

26 Desde o início dos anos 2000, percebe-se que há vários fundos patrimoniais emergindo no Brasil e a grande maioria tem uma origem do setor bancário (QUEIROZ, 2020).

27 PL 4643/2012 da Deputada Federal Bruna Furlan (PSDB/SP); PL 8694/2017 (PLS 16/2015) da Senadora Ana Amélia (PP/RS); PL 8512/2017 (apensado ao PL 6.345/2016) da deputada Federal Professora Dorinha Seabra Rezende (DEM/TO); PLS 160/2017 do Senador Elmano Ferrer (PMDB/PI); PL 7.641/2017 do Deputado Paulo Abi-Ackel (PSDB/MG).

28 Matéria de Edna Simão "MEC que implantar no país modelo de fundo patrimonial comum nos EUA". Disponível em: <https://valor.globo.com/brasil/noticia/2019/09/10/mec-querimplantar-no-pais-modelo-de-fundo-patrimonial-comum-nos-eua.ghtml $>$. Acesso em: 04
} 
senvolvimento e inovação nas universidades federais, busca trazer para o Brasil os investimentos de fundos patrimoniais dos Estados Unidos. O objetivo, segundo a referida matéria, é que os gestores estadunidenses não só apliquem como façam parte do conselho de administração do Fundo Soberano do Conhecimento, que inicialmente contará com um patrimônio de 4,4 mil imóveis, que será administrado por uma associação de direito privado, sem fins lucrativos. Arnaldo Lima, atual Secretário de Educação Superior do Governo Bolsonaro, afirma que o objetivo é criar um fundo patrimonial do MEC para aplicar os recursos e projetos rentáveis ao capital financeiro. O Secretário disse ao jornal Valor Econômico, na matéria acima indicada, que o MEC desenvolverá produtos financeiros para esses agentes, isto é, o fundo patrimonial do MEC articulará os agentes dos fundos patrimoniais das universidades estadunidenses e apresentará as propostas de projetos que atendam aos interesses desses investidores.

Fica evidente, portanto, que, na proposta do Governo Federal, os recursos e as diretrizes da educação superior brasileira serão definidos pelos investidores dos fundos patrimoniais. A concepção de que cabe à universidade pública constituir-se como um negócio lucrativo, garantindo a movimentação do mercado financeiro, não só mantém o padrão dependente de educação superior, como amplia o privatismo exaltado historicamente vigente no Brasil, impondo, aos setores classistas e combativos da classe trabalhadora, a defesa da educação pública e a reafirmação cotidiana de que educação não é mercadoria.

\section{Considerações finais}

As reflexões aqui apresentadas, como parte dos estudos e pesquisas que estão sendo realizados nas universidades públicas, demonstram que um conjunto de alterações está sendo conduzido na política de educação superior, tendo como eixo norteador a concepção da educação superior como um serviço lucrativo.

Se o privatismo exaltado é um elemento estruturante do padrão brasileiro de escola superior, conforme nos indica Fernandes, é necessário apreender as novidades da sua manifestação na atualidade pela articulação de três eixos condutores: (i) o uso do fundo público para financiamento direto e indireto das instituições privadas de ensino superior; (ii) a drástica redução do financiamento

out. 2019 . 
público às instituições públicas, especialmente as universidades federais, no contexto da EC 95/2016 e dos recorrentes contingenciamentos realizados pelo governo federal e, (iii) a criação de um arcabouço jurídico que viabiliza a ação dos fundos patrimoniais nas universidades públicas, com o argumento de que expressam uma modalidade viável de financiamento da educação superior, omitindo que tais fundos constituem, de fato, uma nova estratégia de lucratividade para o capital.

Examinar a agenda do capital para a educação superior, resistir aos seus ataques e apresentar o projeto de universidade pública e gratuita, a serviço dos/as trabalhadores/as são, portanto, as pautas que articulam nossos estudos e nossas lutas em tempos de ofensiva ultraconservadora do capital em crise.

\section{Referências}

AUDITORIA CIDADÃ DA DÍVIDA. Os números da Dívida. Brasília, 2018. Disponível em: < https://auditoriacidada.org.br/wp-content/uploads/ 2018/05/Os-numeros-da-divida-2018.pdf>. Acesso em: 2 jun. 2019.

BERTOLDO, E. Trabalho e educação no Brasil: da centralidade do trabalho à centralidade da política. São Paulo: Instituto Lukács, 2015.

BRASIL. Lei No 10.973, de 02/12/2004. Dispõe sobre incentivos à inovação e à pesquisa científica e tecnológica no ambiente produtivo. Presidência da República. Secretaria Geral. Subchefia para Assuntos Jurídicos. Brasília 2004. Disponível em: <http://www.planalto.gov.br/ccivil_03/_ato2004-2006/2004/ lei/110.973.htm>. Acesso em: 05 jan.2021.

Decreto No 6.096, de 24/04/2007. Institui o Programa de Apoio a Planos de Reestruturação e Expansão das Universidades Federais - REUNI.

Presidência da República. Casa Civil. Subchefia para Assuntos Jurídicos. Brasília, 2007. Disponível em: <http://www.planalto.gov.br/ccivil_03/_ato20072010/2007/decreto/d6096.htm>. Acesso em: 05 jan.2021.

. Lei $\mathrm{N}^{\circ} 13.429$, de 31/03/2017. Dispõe sobre o trabalho temporário nas empresas urbanas e dá outras providências. Presidência da República. Secretaria Geral. Subchefia para Assuntos Jurídicos. Brasília, 2017a. Disponível em: <http://www.planalto.gov.br/ccivil_03/_ato2015-2018/2017/lei/ 113429.htm> Acesso em: 05 jan.2021. 
. Lei No 13.467, de 13/07/2017. Altera a Consolidação das Leis do Trabalho (CLT) para adequar a legislação às novas relações de trabalho. Presidência da República. Secretaria Geral. Subchefia para Assuntos Jurídicos. Brasília, 2017b. Disponível em: < http://www.planalto.gov.br/ccivil_03/_ato20152018/2017/lei/113467.htm> Acesso em: 05 jan.2021.

. Presidência da República. Casa Civil. Constituição da República Federativa do Brasil 1988. Disponível em: < http://www.planalto.gov.br/ccivil_03/ constituicao/constituicao.htm>. Acesso: 02 jan. 2021.

. Presidência da República. Casa Civil. Emenda Constitucional 95 de 15 de dezembro de 2016. Disponível em: < http://www.planalto.gov.br/ ccivil_03/constituicao/emendas/emc/emc95.htm>. Acesso em: 2 jan. 2021.

. Lei no 13.019, de 31 de julho de 2014. Estabelece o regime jurídico das parcerias voluntárias, envolvendo ou não transferências de recursos financeiros, entre a administração pública e as organizações da sociedade civil, em regime de mútua cooperação, para a consecução de finalidades de interesse público; define diretrizes para a política de fomento e de colaboração com organizações da sociedade civil; institui o termo de colaboração e o termo de fomento; e altera as Leis $\mathrm{n}^{\circ}$ s 8.429, de 2 de junho de 1992, e 9.790, de 23 de março de 1999. Disponível em:< http://www.planalto.gov.br/ccivil_03/_ato2011-2014/2014/lei/ 113019.htm>. Acesso em: 17 nov. 2020.

. Câmara dos Deputados. Projeto de Lei PL 4643/2012. Autoriza a criação de Fundo Patrimonial (endowment fund) nas instituições federais de ensino superior. Disponível em: < https://www.camara.leg.br/proposicoesWeb/ prop_mostrarintegra;jsessionid=node01 pmtzqgcrhrg21 rf0amu0x4jjx9409614.n ode 0 ?codteor $=1035343 \&$ filename $=P L+4643 / 2012>$. Acesso em: 02 jan. 2021.

. Câmara dos Deputados. Projeto de Lei PL 6775/2016. Dispõe sobre a criação e o funcionamento de fundos patrimoniais vinculados às instituições públicas e às privadas de interesse público sem fins lucrativos. Disponível em: $<$ https://www.camara.leg.br/proposicoesWeb/prop_mostrarintegra? codteor $=1519319 \&$ filename $=\mathrm{PL}+6775 / 2016>$. Acesso em: 02 jan. 2021.

. Medida provisória no 851, de 10 de setembro de 2018. Autoriza a administração pública a firmar instrumentos de parceria e termos de execução de programas, projetos e demais finalidades de interesse público com organizações gestoras de fundos patrimoniais e dá outras providências. Disponível em: <http://www.planalto.gov.br/ccivil_03/_Ato2015-2018/2018/Mpv/ mpv851.htm>. Acesso em: 17 nov. 2020. 
Lei no 13.800/2019. Autoriza a administração pública a firmar instrumentos de parceria e termos de execução de programas, projetos e demais finalidades de interesse público com organizações gestoras de fundos patrimoniais. Disponível em: <http://www.planalto.gov.br/ccivil_03/_ato2019-2022/2019/ lei/L13800.htm>. Acesso em: 17 nov. 2020.

CHAUÍ, M. A Universidade Operacional. Folha Online, São Paulo, maio 1999. Disponível em: <http://www1.folha.uol.com.br/fol/brasil500/dc_1_3.htm>. Acesso em: 15 abr. 2015.

DUARTE, J. L. do N. Trabalho Docente do Assistente Social nas Federais: contradições e resistências em tempos de intensificação e produtivismo acadêmico. 2017. 467 f. Tese (Doutorado em Serviço Social) - Escola de Serviço Social, Universidade Federal do Rio de Janeiro, Rio de Janeiro, 2017.

FABIANI, P. J. O que são fundos patrimoniais. In: KISIL, M.; FABIANI, P. J.; ALVAREZ, R. Fundos Patrimoniais: criação e gestão no Brasil. São Paulo: Zeppelini Editorial, 2012.

FERNANDES, F. Mudanças Sociais no Brasil. São Paulo: Difel, 1974. Universidade brasileira: reforma ou revolução? 2. ed. São Paulo: Alfa-Omega, 1979.

\section{Capitalismo Dependente e Classes Sociais na América Latina.}

Rio de Janeiro: Zahar Editores, 1981.

A questão da USP. São Paulo: Brasiliense, 1984.

FONTES, V. O Brasil e o capital imperialismo: teoria e história. Rio de Janeiro: EPSJV, UFRJ, 2010.

. Capitalismo filantrópico? - os múltiplos papéis dos APHs em-

presariais. In: Marx e Marxismo. Publicação do Núcleo Interdisciplinar de Estudos sobre Marx e Marxismo - v.8, n.14, jan/jun 2020, p. 15-35. Niterói: Universidade Federal Fluminense, 2020..

IDIS. Proposta de Projeto de Lei - Fundos Patrimoniais Vinculados. Instituto para o Desenvolvimento do Investimento Social - IDIS. São Paulo, 2014. Disponível em: <http://www.secretariadegoverno.gov.br/.arquivos/fundos-patronais>. Acesso em: 20 out. 2018.

LEHER, R. Educação no governo Lula da Silva: a ruptura que não aconteceu. In: Os anos Lula: contribuição para um balanço crítico 2003-2010. Rio de Janeiro: Garamond, 2010. p. 369-412. 
Universidade e heteronomia cultural no capitalismo dependente: um estudo a partir de Florestan Fernandes. Rio de Janeiro: Consequência, 2018. . Desafios ao trabalho de assistentes sociais na educação em tempos de "escola sem mordaça. In: $16^{\circ}$ Congresso Brasileiro de Assistentes Sociais, 2019, Brasília. Anais do 16 CBAS. Disponível em: <https://broseguini.bonino.com.br/ojs/index.php/CBAS/issue/view/1>. Acesso em: 2 jan. 2021.

LENIN, V. O Imperialismo, etapa superior do capitalismo. Campinas, SP; FE/Unicamp, 2011.

LIMA, K. Contrarreforma na Educação Superior: de FHC a Lula. São Paulo: Xamã, 2007.

- Desafio educacional brasileiro e ofensiva ultraconservadora do capital. Revista Universidade e Sociedade, Brasília, ano XXIX, out. 2019. p. 839. Disponível em: < https://www.andes.org.br/sites/universidade_e_sociedade>. Acesso em: 10 jul. 2020.

. Desafios éticos e políticos da luta de classes e o mito da democracia racial em Florestan Fernandes. Revista Katálysis, Florianópolis, v. 20, n. 3, 2017. p. 353-362.

LIMOEIRO-CARDOSO. Florestan Fernandes: a criação de uma problemática. 1996. Disponível em: <http://www.scielo.br/scielo.php?script=sci_arttext\&pid=S0103-40141996000100014> . Acesso em: 20 mar. 2020.

LOPES, L. de F. Advocacy da Lei de Endowments: diálogo com a SecretariaGeral da Presidência da República. In: FABIANI, P. J.; HANAI, A.; PASQUALIN, P.; LEVISKY, R. (orgs.). Fundos Patrimoniais Filantrópicos: Sustentabilidade para causas e organizações. São Paulo: IDIS - Instituto para o Desenvolvimento do Investimento Social, 2019. p. 195-200.

MINTO, L. W. A educação da "miséria": particularidade capitalista e educação superior no Brasil. 2011.326 f . Tese (Doutorado em ) - Pós-Graduação da Faculdade de Educação, Universidade Estadual de Campinas, Campinas, 2011.

As reformas do Ensino Superior no Brasil: o público e o privado em questão. Campinas: Autores Associados, 2006.

MORAES, R. C. Educação superior nos Estados Unidos: história e estrutura. 1. ed. São Paulo: Editora Unesp, 2015.

MORAES, R. C. Modelos internacionais de educação superior: Estados Unidos, França e Alemanha. São Paulo: Editora Unesp, 2017. 
NEVES, L. A nova pedagogia da hegemonia: estratégias do capital para educar o consenso. São Paulo: Xamã, 2005.

PANNUNZIO, E. O modelo da Lei 13.800/19 é obrigatório ou facultativo? In: FABIANI, P. J.; HANIA, A.; PASQUALIN, P.; LEVISKY, R. (orgs.). Fundos Patrimoniais Filantrópicos: Sustentabilidade para causas e organizações. São Paulo: IDIS - Instituto para o Desenvolvimento do Investimento Social, 2019. p. 14-51.

PARTIDO SOCIAL LIBERAL/PSL. 2018. O caminho da prosperidade. Proposta de plano de governo. Disponível em: <https:// flaviobolsonaro.com/ PLANO_DE_GOVERNO_JAIR_BOLSONARO_2018.pdf>. Acesso em: 30 maio 2019.

PASQUALIN, P. Aspectos jurídicos dos fundos patrimoniais filantrópicos. In: FABIANI, P. J.; HANIA, A.; PASQUALIN, P.; LEVISKY, R. (orgs.). Fundos Patrimoniais Filantrópicos: Sustentabilidade para causas e organizações. São Paulo: IDIS - Instituto para o Desenvolvimento do Investimento Social, 2019. p. 14-51.

PRESTES, L. Para onde caminhamos? Aspectos estruturantes e conjunturais da crise na Universidade pública brasileira. 2018.170 f . Dissertação (Mestrado em Serviço Social e Desenvolvimento Regional) - Escola de Serviço Social, Universidade Federal Fluminense, 2018.

QUEIROZ, V. O fundo patrimonial (endowmentfund): a agenda do capital para as universidades brasileiras. Revista Universidade e Sociedade, Brasília, ano XXX, n. 65, p. 43-55, 2020. Disponível em: <https://www.andes.org.br/

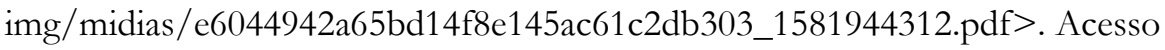
em: 10 mar. 2020.

RODRIGUES, J. dos S. Ainda a educação politécnica: o novo decreto da educação profissional e a permanência da dualidade estrutural. Revista Trabalho, Educação e Saúde, Rio de Janeiro, v. 3, n. 2, p. 259-282, 2005.

RODRIGUES, J. Ainda a educação politécnica: o novo decreto da educação profissional e a permanência da dualidade estrutural. Revista Trabalho, Educação e Saúde, Rio de Janeiro, v. 3 n. 2, 2005. p. 259-282.

RODRIGUES, J. dos S. Os Empresários e a Educação Superior. Campinas: Autores Associados, 2007. 
. Por um programa de transição para a educação: em defesa da concepção marxista de formação politécnica. Caminhos da politecnia: 30 anos da Escola Politécnica de Saúde Joaquim Venâncio. Rio de Janeiro: EPSJV, 2016.

SAVIANI, D. O choque teórico da politecnia. Revista Trabalho, educação e saúde (online), v.1, n.1, p. 131-152, 2003. Disponível em: <http:/ /www.scielo.br/scielo.php?script $=$ sci_arttext\&pid $=$ S1981-77462003000100010>. Acesso em: 10 mar. 2020.

SGUISSARDI, V. Modelo de expansão da educação superior no Brasil: predomínio privado / mercantil e desafios para a regulação e a formação universitária. Educação \& Sociedade, Campinas, v. 29, n. 105, p. 991-1022, set/dez, 2008.

TROTSKY, L. A história da revolução Russa. Rio de Janeiro: Paz e Terra, 1977.

\section{UFLA. Minuta do Programa Institutos e Universidades Empreendedoras}

e Inovadoras - FUTURE-SE. Lavras- MG, 2019. Disponível em: <https:/ / ufla.br/images/arquivos/2019/07-julho/Minuta_Programa_Future-se.pdf $>$. Acesso em: 30 ago. 2019. 